\title{
Effect of Organic Modifier Types on the Physical-Mechanical Properties and Overall Migration of Post-Consumer Polypropylene/Clay Nanocomposites for Food Packaging
}

\author{
Eliezer Velásquez ${ }^{1,2} \mathbb{D}$, Sebastián Espinoza ${ }^{1}$, Ximena Valenzuela ${ }^{1,2}$, Luan Garrido ${ }^{1}$, María José Galotto ${ }^{1,2,3}$, \\ Abel Guarda ${ }^{1,2,3}$ and Carol López de Dicastillo ${ }^{1,2,3, *(D)}$
}

1 Packaging Innovation Center (LABEN-Chile), University of Santiago of Chile (USACH), Obispo Umaña 050, Santiago 9170201, Chile; eliezer.velasquez@usach.cl (E.V.); sebastian.espinoza@usach.cl (S.E.); ximena.valenzuela@usach.cl (X.V.); luan.garrido@usach.cl (L.G.); maria.galotto@usach.cl (M.J.G.); abel.guarda@usach.cl (A.G.)

2 Center for the Development of Nanoscience and Nanotechnology (CEDENNA), University of Santiago of Chile (USACH), Obispo Umaña 050, Santiago 9170201, Chile

3 Food Science and Technology Department, Technological Faculty, University of Santiago of Chile (USACH), Obispo Umaña 050, Santiago 9170201, Chile

* Correspondence: analopez.dediscastillo@usach.cl; Tel.: +56-951377492

check for

updates

Citation: Velásquez, E.; Espinoza, S.; Valenzuela, X.; Garrido, L.; Galotto,

M.J.; Guarda, A.; López de Dicastillo, C. Effect of Organic Modifier Types on the Physical-Mechanical

Properties and Overall Migration of Post-Consumer Polypropylene/Clay Nanocomposites for Food Packaging. Polymers 2021, 13, 1502. https:/ / doi. org/10.3390/polym13091502

Academic Editor: Luis Cabedo Mas

Received: 14 April 2021

Accepted: 3 May 2021

Published: 7 May 2021

Publisher's Note: MDPI stays neutral with regard to jurisdictional claims in published maps and institutional affiliations.

Copyright: (c) 2021 by the authors. Licensee MDPI, Basel, Switzerland. This article is an open access article distributed under the terms and conditions of the Creative Commons Attribution (CC BY) license (https:/ creativecommons.org/licenses/by/ $4.0 /)$

\begin{abstract}
The deterioration of the physical-mechanical properties and loss of the chemical safety of plastics after consumption are topics of concern for food packaging applications. Incorporating nanoclays is an alternative to improve the performance of recycled plastics. However, properties and overall migration from polymer/clay nanocomposites to food require to be evaluated case-by-case. This work aimed to investigate the effect of organic modifier types of clays on the structural, thermal and mechanical properties and the overall migration of nanocomposites based on 50/50 virgin and recycled post-consumer polypropylene blend (VPP/RPP) and organoclays for food packaging applications. The clay with the most hydrophobic organic modifier caused higher thermal stability of the nanocomposites and greater intercalation of polypropylene between clay mineral layers but increased the overall migration to a fatty food simulant. This migration value was higher from the 50/50 VPP/RPP film than from VPP. Nonetheless, clays reduced the migration and even more when the clay had greater hydrophilicity because of lower interactions between the nanocomposite and the fatty simulant. Conversely, nanocomposites and VPP/RPP control films exhibited low migration values in the acid and non-acid food simulants. Regarding tensile parameters, elongation at break values of PP film significantly increased with RPP addition, but the incorporation of organoclays reduced its ductility to values closer to the VPP.
\end{abstract}

Keywords: post-consumer polypropylene; clay; organic modifier; nanocomposite; migration

\section{Introduction}

Polypropylene (PP) is a thermoplastic polymer commonly used to manufacture kitchen utensils, automobile parts, textiles, pipes and packaging. PP was the most demanded plastic by European converters in 2018, representing 19\% of the total produced resins (51.2 million tons) [1]. During the last decades, recycling and valorization of postconsumer polypropylene (RPP) have been a global concern to reduce its accumulation in natural environments. Although PP is recyclable, its properties are highly affected due to the mechanical stresses, thermal cycles and degradation reactions during its reprocessing [2]. In an attempt to improve the properties of RPP, nanoparticles, such as carbon nanotubes, zinc oxide and nanoclays, among others, have been incorporated [3].

The use of nanoparticles leads to a high polymer/nanofiller interphase area allowing an adequate energy transfer through the plastic matrix that undergoes stress. Nanoclays are specially used due to their low cost and commercial availability. They are laminar 
aluminosilicates that can enhance the stiffness and strength of the plastics through the intercalation of the polymer chains between clay galleries [4]. Most of the studies on $\mathrm{PP} /$ clay nanocomposites have used virgin resin, and only a few works have focused on the reinforcement of RPP where the nanofillers can potentially act as performance improvers of the degraded plastic, which has a molar mass distribution different than VPP, depending on the grade and source of the recycled polymer [5-8]. However, these scarce studies have only focused on the morphology and some rheological-mechanical aspects and not on the chemical safety and overall migration of the nanocomposites, which is essential for food packaging materials to guarantee human health and consumer acceptability. Advances in this research line are highly required because: (i) little information on the safety of nanocomposite materials is available; (ii) the variation in the RPP properties and the interactions between components of the nanocomposite and foodstuff, as a function of the type of polymer and organic modifier of the nanoclay, need to be addressed; (iii) the growing new developments of nanotechnology-based materials for food packaging [9-12].

The bentonite clay is classified under the European Union Regulation 10/2011 ( $\mathrm{N}^{\circ} \mathrm{FCM}$ 393) as a substance without restriction for food packaging. However, clay minerals need to be organically modified in order to increase their compatibility with hydrophobic polymers as PP. In this regard, a report about the conditions to use ethylene-based polymer/organically modified clay nanocomposites as food contact material from EFSA (European Food Safety Authority) has ruled that a case-by-case safety study is required for each nanocomposite as a function of the type of clay and organic modifier [13]. Therefore, the migration phenomena of substances from polymer/clay nanocomposites to food are still controversial and depend on the type of polymer matrix and food simulant, type and concentration of clay and test conditions [14].

Recently, release studies mainly focused on the migration of Si and $\mathrm{Al}$ from polymer/clay nanocomposites based on virgin LDPE, PET and PP have been reported [15-20]. Still, safety studies of nanocomposites based on post-consumer plastics have been scarcely carried out [21]. In addition, migration tests become more relevant for recycled plastics due to the high concentration of low molar mass species or oligomers resulting from recycling, which increase substance release [9]. According to our review, no studies have been published about overall migration from RPP and organically modified clay-nanocomposites for food packaging applications. Therefore, in this work, the effect of organic modifier types of a nanoclay (nanoclay hydrophilicity) on the structure, crystallinity, thermal parameters, mechanical properties and overall migration of RPP-based nanocomposites films to different food simulants was analyzed.

\section{Materials and Methods}

\subsection{Materials}

Homopolymer grade virgin polypropylene pellets (VPP) was supplied by Petroquim, S.A (Santiago, Chile) (density: $0.0905 \pm 0.005 \mathrm{~g} \mathrm{~mL}^{-1}$ ). Recycled post-consumer polypropylene pellets (RPPs) were provided by Comberplast, S.A (San Bernardo, Chile). Two organically modified mineral clays (OCs) with different surfactants were used: (i) Non-polar-modified organoclay, OCN, (bulk density: $200-500 \mathrm{~kg} \mathrm{~m}^{-3}$ ) is a montmorillonite clay modified with a quaternary ammonium salt of tert-alkyl amine; (ii) OCP (bulk density: $300 \mathrm{~kg} \mathrm{~m}^{-3}$ ) is a montmorillonite with an organic modifier containing polar groups (alkyl-T-bis-2-hydroxyalkyl quaternary ammonium).

\subsection{Preparation of RPP-Based Nanocomposites}

Clay/polymer nanocomposites films based on 50/50 VPP/RPP blend (NC) were obtained because concentrations above $50 \mathrm{wt} \%$ of RPP caused simultaneous and significant deterioration of all mechanical parameters (see supplementary file Table S1). Two types of clays $(\mathrm{OCN}$ and $\mathrm{OCP}$ ) were incorporated at concentrations of 1,3 and $5 \mathrm{wt} \%$ with respect to the total mass of nanocomposite, resulting in six different nanocomposites: NC-1OCN, NC-3OCN, NC-5OCN, NC-1OCP, NC-3OCP and NC-5OCP. 
Films were obtained by cast-extrusion in a twin-screw extruder Labtech Scientific LTE-20-40 (Samutprakarn, Thailand), with a temperature profile of $180-190{ }^{\circ} \mathrm{C}$, a screw speed of $20 \mathrm{rpm}$ and $40 \%$ torque. The VPP and RPP pellets were previously dried at $100{ }^{\circ} \mathrm{C}$, and the clays were dried at $40^{\circ} \mathrm{C}$ in a vacuum oven, both for $48 \mathrm{~h}$. Blends were homogenized before adding to the extruder hopper. Additionally, VPP, RPP and 50/50 VPP/RPP control films were prepared under the same conditions.

\subsection{Characterization of the Films}

\subsubsection{Structural Analysis}

The clays and nanocomposites were characterized by X-ray diffraction (XRD) in order to determine the interlaminar distance in the clays and the type of structure of the nanocomposites. The equipment used was a Siemens D5000 brand X-ray diffractometer (30 mA, $40 \mathrm{KV}$, München, Germany). The samples were explored in reflection mode using an incident $\mathrm{Cu}-\mathrm{K} \alpha$ radiation and a step of $0.02^{\circ} \mathrm{min}^{-1}$, in a range $2 \theta=2-9^{\circ}$. The interlaminar distance $\left(\mathrm{d}_{001}\right)$ was determined using Bragg's Law following Equation (1):

$$
\operatorname{sen}(\theta)=\frac{\mathrm{n} \lambda}{2 \mathrm{~d}}
$$

where $\mathrm{d}$ is the interlaminar distance in the clay, $\theta$ is the angle between the incident rays and the scattering plane, $\mathrm{n}$ is equal to 1 and $\lambda$ is the wavelength of the X-ray $(0.154 \mathrm{~nm})$.

\subsubsection{Thermal Analysis}

The thermal stability of the samples (6-8 mg) was determined in a Mettler Toledo Gas Controller GC20 Stare System TGA/DSC equipment using a heating program from 30 to $600{ }^{\circ} \mathrm{C}$ with a heating rate of $10^{\circ} \mathrm{C} \mathrm{min}-1$ under nitrogen atmosphere. The decomposition initiation temperature at $5 \%$ mass loss $\left(\mathrm{T}_{\text {onset }}\right)$, the temperature at the maximum degradation rate $\left(T_{d}\right)$ and the mass loss at $T_{d}$ were determined.

DSC analysis was carried out in a calorimeter Mettler-Toledo model STAR 822e (Greinfensee, Switzerland) coupled to a cooling unit (HAAKE, USA). The samples in aluminum capsules $(6-8 \mathrm{mg}$ ) were subjected to two thermal scans, heating from 25 to $250{ }^{\circ} \mathrm{C}$ and cooling from 250 to $25^{\circ} \mathrm{C}$, at a constant speed of $10{ }^{\circ} \mathrm{C} \mathrm{min}{ }^{-1}$ under nitrogen atmosphere. The melting $\left(\mathrm{T}_{\mathrm{m}}\right)$ and crystallization temperatures $\left(\mathrm{T}_{\mathrm{c}}\right)$, melting $\left(\Delta \mathrm{H}_{\mathrm{m}}\right)$ and crystallization enthalpies $\left(\Delta \mathrm{H}_{\mathrm{C}}\right)$ and the percent crystalline fraction were registered. The crystallinity was calculated from Equation (2), relating the PP melting heat $\left(\Delta \mathrm{H}_{\mathrm{m}}\right)$ of the sample and the theoretical melting heat of $100 \%$ crystalline polypropylene $\left(\Delta \mathrm{H}_{100}\right)$ :

$$
\mathrm{X}_{\mathrm{c}}=\frac{\Delta \mathrm{H}_{\mathrm{m}}}{\Delta \mathrm{H}_{100} \times \mathrm{X}_{\mathrm{PP}}} * 100(\%)
$$

where $X_{c}$ is the percentage of crystalline fraction (\%), $\Delta \mathrm{H}_{\mathrm{m}}$ is the melting enthalpy of the sample $\left(\mathrm{J} \mathrm{g}^{-1}\right), \Delta \mathrm{H}_{100}$ is the melting enthalpy of fully crystalline polypropylene equal to 206.7 $\mathrm{J} \mathrm{g}^{-1}$ [22] and $\mathrm{X}_{\mathrm{PP}}$ is the mass fraction of polypropylene in the film (\%). The results of thermal parameters and crystallinity were reported as the mean and standard deviation of two measurements.

\subsubsection{Mechanical Properties}

Tensile parameters of the films such as Young's modulus (YM), tensile strength (TS) and elongation at break (EB) were determined in a Zwick Roell universal machine (model BDO-FB 0.5 TH, Ulm, Germany) according to the ASTM D882 normative. Specimens with dimensions $16.5 \mathrm{~cm} \times 2.4 \mathrm{~cm}$ were cut and conditioned at $23{ }^{\circ} \mathrm{C}$ for $48 \mathrm{~h}$ in a desiccator with $\mathrm{RH}$ of $50 \% \pm 10 \%$. The separation distance between the jaws was $50 \mathrm{~mm}$ and the crosshead speed was $500 \mathrm{~mm} \mathrm{~min}^{-1}$. The results were reported as the mean and standard deviation of 15 measurements. 


\subsubsection{Overall Migration Analysis}

Overall migration tests were conducted according to EU Regulation $N^{\circ} 10 / 2011$ and UNE-EN 1186 normative. The nanocomposites that reached the best tensile performance, VPP, RPP and VPP/RPP 50/50 control films, were analyzed. Double-sided, total immersion migration tests were conducted using an area-to-volume of food simulant ratio of $6 \mathrm{dm}^{2} \mathrm{~L}^{-1}$. Used as acidic, non-acid hydrophilic and fatty food simulants were $3 \%$ acetic acid, $10 \%$ ethanol solutions and isooctane, respectively. Tests were conducted at $40{ }^{\circ} \mathrm{C}$ for 10 days in the acid and non-acid simulant, and at $20^{\circ} \mathrm{C}$ for $48 \mathrm{~h}$ in the substitute fatty food simulant according to the substitute conventional conditions for isooctane of UNE EN 1186 normative.

After the contact time, each food simulant was transferred to dry crucibles that were previously weighed. Food simulants were evaporated until reaching constant mass and the overall mass that migrated per $\mathrm{dm}^{2}$ was quantified by gravimetry. The results were reported as the mean and standard deviation of four measurements.

\subsection{Statistical Analysis}

Data were analyzed through an analysis of variance (ANOVA) and Fisher's multiple range test using the Statgraphic plus 5.1 program. The experimental design was the random type where a $p$-value less than 0.05 indicated significant differences in the measurements between samples and were highlighted with different superscript letters.

\section{Results}

\subsection{Structural Properties}

Nanocomposites presented a combination of intercalated and tactoid structures except nanocomposites containing OCN clay at 1 and $3 \mathrm{wt} \%$, whose XRD diffractograms evidenced only intercalated structures indicating better nanoclay dispersion. Despite differences in polarity between PP and clays, intercalated structures were obtained by high shear and dispersive forces during extrusion. The highest hydrophobicity of the OCN organic modifier promoted greater compatibility with PP chains and their better intercalation between clay mineral layers. As is shown in Table 1 and Figure 1, OCN pure clay presented two peaks at $3.32^{\circ}$ and $7.03^{\circ}$ (peaks a and b) while nanocomposites with 1 and $3 \mathrm{wt} \%$ OCN displayed three peaks (c, $\mathrm{d}$ and e), all of them associated with intercalated structures and increments of interlaminar distance. In contrast, tactoid structures or agglomerates were formed at $5 \mathrm{wt} \%$ of OCN evidenced by a reduction of the interlayer space (peak e) (Table 1).

Table 1. The $2 \theta$ angles and interlaminar distances in the pure clays and nanocomposites.

\begin{tabular}{|c|c|c|c|c|c|c|}
\hline \multirow{2}{*}{$\begin{array}{c}\text { Sample } \\
\text { Clays }\end{array}$} & \multicolumn{3}{|c|}{$2 \theta$} & \multicolumn{3}{|c|}{ d ( $(\AA)$} \\
\hline & a & \multicolumn{2}{|c|}{$\mathbf{b}$} & \multicolumn{2}{|c|}{ a } & $\mathbf{b}$ \\
\hline OCN & 3.32 & \multicolumn{2}{|c|}{7.03} & \multirow{2}{*}{\multicolumn{2}{|c|}{26.6}} & 12.6 \\
\hline OCP & 3.68 & \multicolumn{2}{|c|}{-} & & & - \\
\hline Film & c & d & e & c & d & e \\
\hline NC-1OCN & 2.32 & 4.52 & 6.69 & 38.0 & 19.5 & 13.2 \\
\hline NC-3OCN & 2.49 & 4.67 & 6.74 & 35.4 & 18.9 & 13.1 \\
\hline NC-5OCN & 2.69 & 5.08 & 7.53 & 32.8 & 17.4 & 11.7 \\
\hline NC-1OCP & 2.25 & 4.47 & 6.74 & 39.2 & 19.7 & 13.1 \\
\hline $\mathrm{NC}-3 \mathrm{OCP}$ & 2.35 & 4.59 & 6.76 & 37.5 & 19.2 & 13.1 \\
\hline NC-5OCP & 2.61 & 4.78 & 6.82 & 33.8 & 18.5 & 12.9 \\
\hline
\end{tabular}




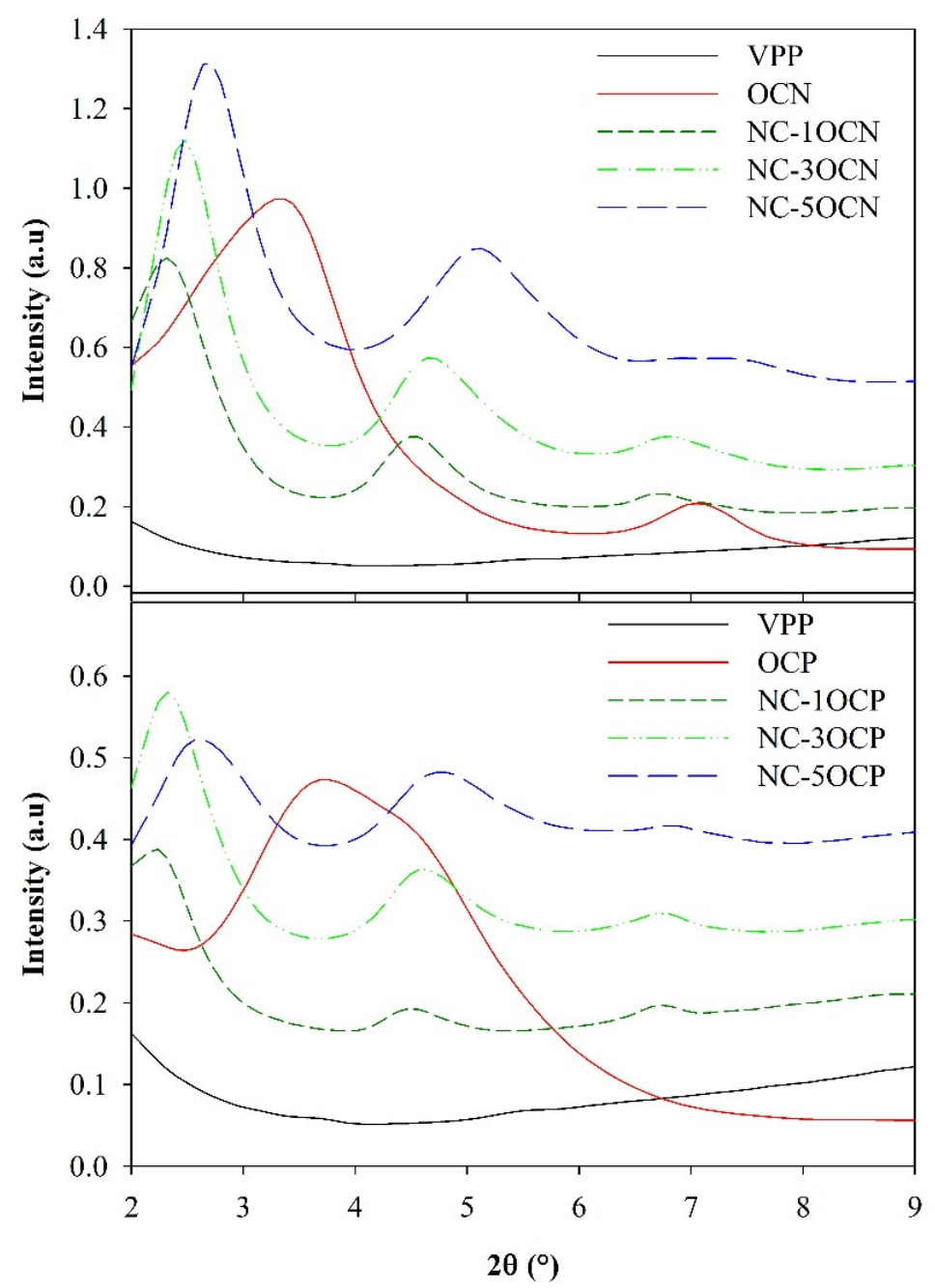

Figure 1. XRD diffractograms of organoclays OCN and OCP, and their corresponding nanocomposites.

The reduction of the interlaminar distance can be attributed to partial decomposition of the organic modifier confined between clay mineral layers, as it has been reported for clay/polymer nanocomposites [21,23]. This phenomenon exhibited a more significant effect on nanocomposites with OCP evidenced through a greater reduction of the interlayer space regardless of clay concentration, from 24 to $12.9-19.7 \AA$ (peaks d and e, Table 1). Likewise, the chain intercalation was diminished and lower interlaminar distances were obtained when clay concentration in the nanocomposites increased (Table 1).

On the other hand, the diffractogram of pure OCP presented the characteristic peak of this clay at $3.68^{\circ}$ (Figure 1). Meanwhile, nanocomposites NC-OCP presented three peaks, the one at lower angles associated with an increase of the interlayer distance (peak c) and the other two peaks related to the reduction of the interlaminar distance (peaks $\mathrm{d}$ and e), resulting in combined intercalated/tactoid structures (Table 1).

\subsection{Thermal Properties}

\subsubsection{Differential Scanning Calorimetry}

During the first heating process, VPP film presented a unique endothermic transition at $164.5^{\circ} \mathrm{C}$, corresponding to the melting point of this polymer (Table 2). RPP-based films showed another endothermic transition at $124{ }^{\circ} \mathrm{C}$, which indicated the presence of traces of high-density polyethylene (HDPE), low-density linear polyethylene (LLDPE) or their blends due to their close melting transitions, as principal pollutants of the RPP. These two 
transitions were also found separately by Vynche et al. (2020) for recycled polypropylene from electronic equipment with known HDPE composition (10 wt \%) [24]. Traces of several polymers can remain commonly mixed with post-consumer PP after collection and separation during the recycling process, especially LLDPE and HPDE, because of the similarity between their specific gravity and combined uses in the same article [25]. For example, recycled plastic caps are mainly composed of PP, but LLDPE and HDPE are used to manufacture part of seal caps, plugs and flip caps.

Table 2. DSC parameters and crystallinities of the PP films.

\begin{tabular}{|c|c|c|c|c|c|c|}
\hline \multirow{2}{*}{ Films } & \multicolumn{6}{|c|}{ First Heating Process } \\
\hline & $\mathrm{T}_{\mathrm{m} 1}\left({ }^{\circ} \mathrm{C}\right)$ & $\Delta \mathrm{H}_{\mathrm{m} 1}\left(\mathrm{~J} \mathrm{~g}^{-1}\right)$ & $\mathrm{T}_{\mathrm{m} 2}\left({ }^{\circ} \mathrm{C}\right)$ & $\mathrm{T}_{\mathrm{m} 3}\left({ }^{\circ} \mathrm{C}\right)$ & $\Delta \mathrm{H}_{\mathrm{m} 2}\left(\mathrm{~J} \mathrm{~g}^{-1}\right)$ & $X_{c}(\%)$ \\
\hline VPP & - & - & $164.5 \pm 1.3^{\mathrm{ab}}$ & - & $102.1 \pm 7.1^{\mathrm{c}}$ & $49.4 \pm 3.4^{b}$ \\
\hline $\mathrm{RPP}$ & $124.0 \pm 0.3^{\mathrm{a}}$ & $2.18 \pm 0.05^{\mathrm{c}}$ & $165.4 \pm 1.7^{\mathrm{b}}$ & - & $89.6 \pm 0.1^{\mathrm{a}}$ & $43.3 \pm 0.1^{\mathrm{a}}$ \\
\hline 50VPP/50RPP & $123.6 \pm 0.7^{\mathrm{a}}$ & $0.63 \pm 0.16^{b}$ & $165.6 \pm 0.7^{b}$ & - & $101.6 \pm 1.6^{\mathrm{c}}$ & $49.2 \pm 0.8^{\mathrm{b}}$ \\
\hline NC-1OCN & $123.9 \pm 0.1^{\mathrm{a}}$ & $0.63 \pm 0.06^{b}$ & $165.6 \pm 0.4^{b}$ & - & $98.5 \pm 1.2^{b c}$ & $48.1 \pm 0.6^{b}$ \\
\hline $\mathrm{NC}-3 \mathrm{OCN}$ & $124.0 \pm 0.2^{\mathrm{a}}$ & $0.60 \pm 0.10^{\mathrm{ab}}$ & $164.6 \pm 1.2^{\mathrm{ab}}$ & $167.6 \pm 0.6^{\mathrm{a}}$ & $97.7 \pm 5.5^{b c}$ & $48.7 \pm 2.7^{b}$ \\
\hline $\mathrm{NC}-5 \mathrm{OCN}$ & $124.5 \pm 0.8^{\mathrm{a}}$ & $0.52 \pm 0.19^{a b}$ & $163.3 \pm 0.2^{\mathrm{a}}$ & $167.2 \pm 0.8^{a}$ & $96.9 \pm 1.6^{\mathrm{abc}}$ & $49.3 \pm 0.8^{b}$ \\
\hline NC-1OCP & $123.7 \pm 0.4^{\mathrm{a}}$ & $0.48 \pm 0.04^{\mathrm{ab}}$ & $163.8 \pm 0.6^{\mathrm{ab}}$ & $166.9 \pm 0.6^{\mathrm{a}}$ & $100.6 \pm 0.7^{c}$ & $49.2 \pm 0.3^{b}$ \\
\hline $\mathrm{NC}-3 \mathrm{OCP}$ & $124.7 \pm 0.1^{\mathrm{a}}$ & $0.30 \pm 0.04^{\mathrm{a}}$ & $163.9 \pm 0.1^{\mathrm{ab}}$ & $167.6 \pm 0.9^{a}$ & $95.2 \pm 2.5^{a b c}$ & $47.5 \pm 1.2^{b}$ \\
\hline NC-5OCP & $124.4 \pm 0.5^{\mathrm{a}}$ & $0.58 \pm 0.18^{b}$ & $164.7 \pm 0.1^{a b}$ & $167.6 \pm 0.4^{\mathrm{a}}$ & $91.6 \pm 1.6^{\mathrm{ab}}$ & $46.7 \pm 0.8^{a b}$ \\
\hline
\end{tabular}

\begin{tabular}{|c|c|c|c|c|}
\hline \multirow{2}{*}{ Films } & \multicolumn{4}{|c|}{ Cooling Process } \\
\hline & $\mathrm{T}_{\mathrm{c} 1}\left({ }^{\circ} \mathrm{C}\right)$ & $\Delta H_{\mathrm{c} 1}\left(\mathrm{~J} \mathrm{~g}^{-1}\right)$ & $\mathrm{T}_{\mathrm{c} 2}\left({ }^{\circ} \mathrm{C}\right)$ & $\Delta H_{\mathrm{c} 2}\left(\mathrm{~J} \mathrm{~g}^{-1}\right)$ \\
\hline VPP & - & - & $113.6 \pm 0.4^{\mathrm{a}}$ & $129.9 \pm 10.5^{c}$ \\
\hline $\mathrm{RPP}$ & $105.6 \pm 0.1^{a}$ & $1.94 \pm 0.01^{c}$ & $123.4 \pm 0.1^{b c}$ & $110.9 \pm 1.2^{\mathrm{a}}$ \\
\hline 50VPP/50RPP & $105.8 \pm 0.1^{\mathrm{a}}$ & $0.41 \pm 0.11^{\mathrm{a}}$ & $123.7 \pm 0.3^{c}$ & $122.6 \pm 4.6^{\mathrm{abc}}$ \\
\hline NC-1OCN & $105.6 \pm 0.2^{a}$ & $0.33 \pm 0.03^{a}$ & $123.1 \pm 0.2^{b c}$ & $117.0 \pm 2.1^{\mathrm{ab}}$ \\
\hline NC-3OCN & $107.3 \pm 2.4^{\mathrm{a}}$ & - & $123.4 \pm 0.4 \mathrm{bc}$ & $114.1 \pm 9.4^{\mathrm{ab}}$ \\
\hline NC-5OCN & $105.4 \pm 0.1^{\mathrm{a}}$ & $0.32 \pm 0.04^{\mathrm{a}}$ & $122.9 \pm 0.4^{b}$ & $117.6 \pm 1.8^{a b c}$ \\
\hline NC-1OCP & $105.4 \pm 0.1^{\mathrm{a}}$ & $0.56 \pm 0.02^{b}$ & $123.2 \pm 0.0^{b c}$ & $125.7 \pm 2.5^{b c}$ \\
\hline NC-3OCP & $105.6 \pm 0.2^{a}$ & $0.33 \pm 0.02^{\mathrm{a}}$ & $123.0 \pm 0.2^{b}$ & $114.4 \pm 3.7^{\mathrm{ab}}$ \\
\hline NC-5OCP & $105.6 \pm 0.2^{a}$ & $0.40 \pm 0.01^{\mathrm{a}}$ & $123.0 \pm 0.1^{b}$ & $111.0 \pm 4.2^{\mathrm{a}}$ \\
\hline
\end{tabular}

$\mathrm{X}_{\mathrm{c}}$ corresponds to PP crystallinity. Superscripts a-c indicate significant differences for the same parameter among films according to the ANOVA analysis and Fisher LSD test $(p<0.05)$.

Besides, the melting peak of PP can be associated with homopolymer or copolymer polypropylene in the post-consumer material, considering both polymer grades have similar melting behavior [24]. Regarding the melting transition of nanocomposites, the thermograms manifested two shoulders at 164 and $167^{\circ} \mathrm{C}$ approx., associated with the formation of different crystalline structures, excluding nanocomposites at $1 \mathrm{wt} \% \mathrm{OCN}$.

All films had a highly ordered structure with similar polypropylene crystallinities of $49 \%$ but decreased to $43 \%$ for the pure RPP film. This fact can be attributed to a hindrance of PP chain packing caused by a greater portion of pollutant polymers with different chemical structures in the RPP sample. Specifically, polyethylene, a common pollutant of RPP, whose highest concentration in the RPP film was demonstrated through the highest heat $\left(\Delta \mathrm{H}_{\mathrm{m} 1}\right)$ required for its melting (Table 2$)$. In the case of linear HDPE, its higher mobility can inhibit PP crystallization before phase separation, similarly as reported for virgin PP/HDPE blends for electrical and electronic applications [24]. Besides, similar crystallinities for nanocomposites revealed the absence of a nucleating effect of the clays on VPP/RPP blend and only promoted different crystal structures, especially at high clay concentration.

During the cooling process, VPP film showed a single exothermic transition at $113.6^{\circ} \mathrm{C}$ corresponding to the crystallization from the molten polymer (Table 2). Meanwhile, RPPbased films presented two transitions related to PP and PE crystallizations at 123 and $105^{\circ} \mathrm{C}$, respectively, confirming the presence of LLDPE and/or HDPE. The crystallization 
temperature found in the recycled material around $105^{\circ} \mathrm{C}$ was between the values reported for virgin LLDPE and HPDE [25]. Likewise, the crystallization temperature displacement to higher values, from $113{ }^{\circ} \mathrm{C}$ for VPP to $123{ }^{\circ} \mathrm{C}$ for RPP-based films, can be explained through the acceleration of the crystal formation by the nucleation action of the recycled polymer chains with lower molar mass than VPP. The molar mass reduction of the PP and other polyolefins due to thermal-mechanical degradation during reprocessing has been previously reported [26,27]. Likewise, a higher enthalpy $\left(\Delta \mathrm{H}_{\mathrm{c} 1}\right)$ of RPP film indicated a higher PE proportion in this sample, as was expected.

The slight differences between enthalpies of the thermal transitions in the nanocomposites can be associated with heterogeneities of the recycled polymer batch in regards to pollutant composition and molar mass distribution.

\subsubsection{Thermogravimetric Analysis}

TGA and DTG curves are shown in Figure 2. The onset decomposition temperatures of the RPP-based films without nanoclay were lower than the temperature values of the VPP film (Table 3). The same tendency was observed for maximum degradation rate temperatures up to a lesser extent. This fact is in concordance with the greater susceptibility of the degraded shorter chains in the RPP to thermal decomposition. However, TGA parameters of the blend with $50 \mathrm{wt} \%$ of RPP remained close to the parameters of the VPP film.
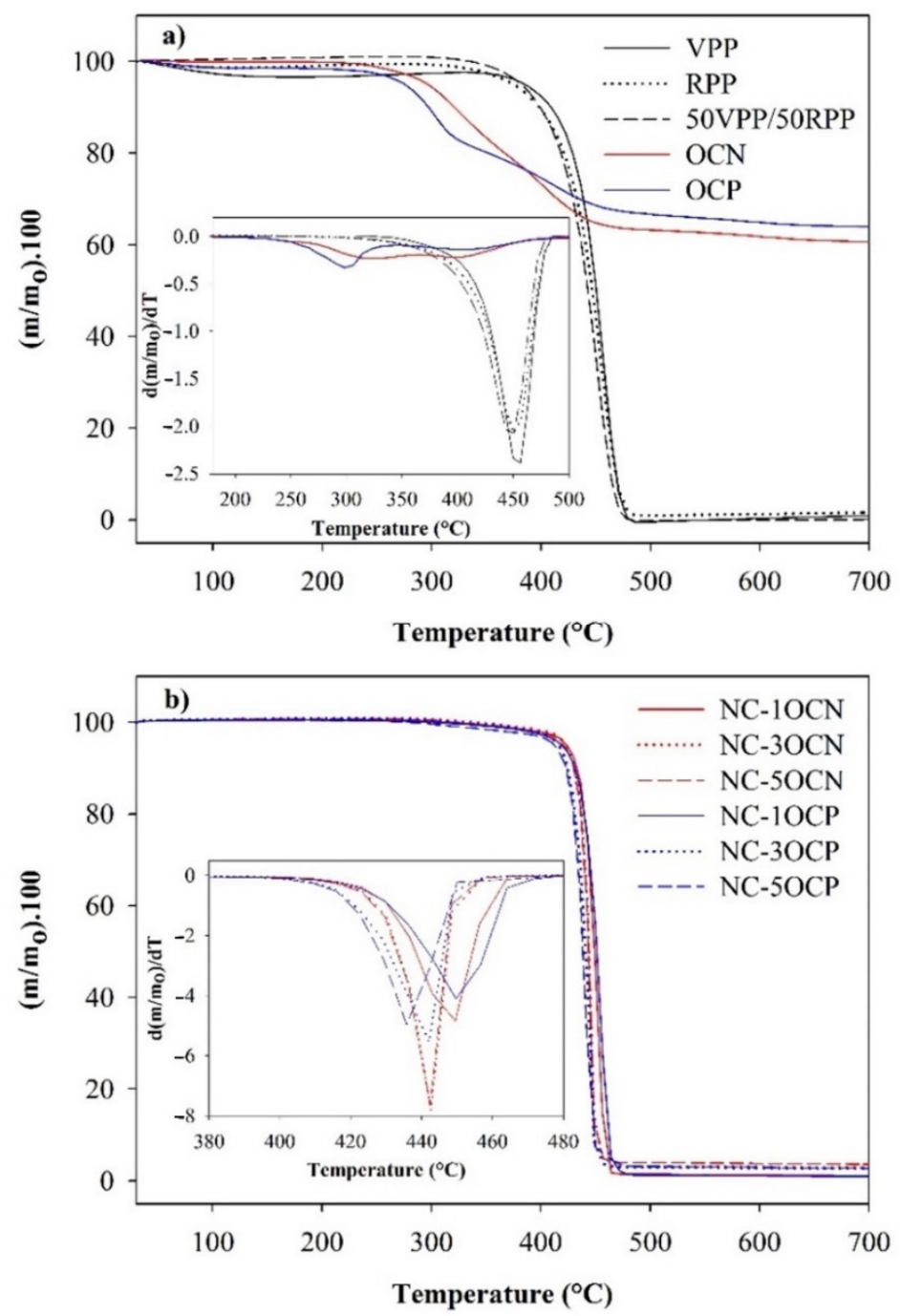

Figure 2. TGA and DTG of (a) organoclays and control films and (b) nanocomposites. 
Table 3. TGA parameters of PP films and organoclays.

\begin{tabular}{cccc}
\hline Samples & $\mathbf{T}_{\mathbf{o n s e t}}\left({ }^{\circ} \mathbf{C}\right)$ & $\mathbf{T}_{\mathbf{d}}\left({ }^{\circ} \mathbf{C}\right)$ & Mass Loss at $\left.\mathbf{T}_{\mathbf{d}} \mathbf{( w \mathbf { t }} \mathbf{\%}\right)$ \\
\hline VPP & 384.5 & 457.1 & 65.6 \\
RPP & 374.5 & 454.8 & 65.6 \\
$50 \mathrm{VPP} / 50 \mathrm{RPP}$ & 381.8 & 451.1 & 66.5 \\
\hline NC-1OCN & 423.6 & 450.1 & 55.0 \\
NC-3OCN & 423.3 & 444.1 & 50.9 \\
NC-5OCN & 420.6 & 443.7 & 50.7 \\
\hline NC-1OCP & 418.8 & 452.7 & 56.3 \\
NC-3OCP & 416.3 & 441.8 & 53.3 \\
NC-5OCP & 412.0 & 439.0 & 52.4 \\
\hline OCN & 296.4 & 327 and 402 & 27.2 \\
OCP & 267.2 & 299 and 404 & 27.1 \\
\hline
\end{tabular}

$\mathrm{T}_{\text {onset }}$ and $\mathrm{T}_{\mathrm{d}}$ correspond to onset decomposition at $5 \mathrm{wt} \%$ mass loss and maximum degradation rate temperatures, respectively.

On the other hand, the incorporation of nanoclays into the VPP/RPP blend improved its thermal stability shifting onset decomposition at higher $\mathrm{T}_{\text {onset }}$ values, with a less significant effect on nanocomposites with OCP. These results agreed with (i) the lower $\mathrm{T}_{\text {onset }}$ for pure OCP $\left(267.2^{\circ} \mathrm{C}\right)$ compared to OCN $\left(296.4^{\circ} \mathrm{C}\right)$, indicating that earlier degradation of the organic modifier of OCP accelerated the decomposition of the nanocomposite, and (ii) the organic surfactant of pure $\mathrm{OCP}$ degraded with a maximum rate at a lower temperature $\left(299^{\circ} \mathrm{C}\right)$ than $\mathrm{OCN}\left(327^{\circ} \mathrm{C}\right)$ (Table 3). Both organic modifiers degraded in two stages according to the confinement of the surfactant between clay mineral layers, as is shown in Figure 2. These phenomena are observed during TGA analysis of the films and clays but it is worth mentioning that extrusion temperature for obtaining films $\left(180-190^{\circ} \mathrm{C}\right)$ was far below $\mathrm{T}_{\text {onset }}$ of the pure clays.

In addition, regardless of the type of clay, the decomposition tended to start at lower $T_{\text {onset }}$ values when clay concentration was increased. Meanwhile, $T_{d}$ remained practically unchangeable in the nanocomposites compared to the control VPP/RPP blend when $1 \mathrm{wt} \%$ of the nanoclay was incorporated but decreased at higher concentrations ( 3 and $5 \mathrm{wt} \%$ ). This fact can be attributed to a higher amount of the nanofiller poorly attached to the PP matrix at a higher concentration of clay, which tended to decompose, although less significantly for OCN with a more hydrophobic organic modifier. Nonetheless, regardless of the type of clay, all nanocomposites had mass losses lower than the VPP/RPP control film at the maximum degradation rate.

\subsection{Mechanical Properties}

The tensile parameters of the 50VPP/50RPP blend were between values of the VPP and RPP films. Increasing RPP concentration deteriorated the mechanical performance of the films, as was expected (Table 4). The YM and the TS of the films decreased with RPP incorporation possible due to several factors: (i) RPP was composed of short chains with lower molar masses compared to VPP chains, reducing stiffness and TS because oligomers did not support stress forces during traction [3], and (ii) the presence of PE and other possible pollutants in the RPP film, such as copolymer grade polypropylene containing ethylene, could have affected the stress transfer based on miscibility differences between polymers $[24,28]$. Likewise, according to the thermal analysis, the lowest rigidity of the RPP film can also be associated with its lowest crystallinity (see Table 2).

Deformation at break values drastically increased as a function of RPP concentration in films without clay, showing a 2.8 and 9.6-fold increase with respect to virgin material for VPP/RPP 50/50 blend and 100\% RPP sample, respectively. This fact can be associated with the presence of ductile polymers such as polyethylene in the RPP. For example, EB values above $800 \%$ have been reported for several LLDPE and HDPE grades $[25,29,30]$. 
Table 4. Tensile parameters of PP films.

\begin{tabular}{cccc}
\hline Films & YM (MPa) & TS (MPa) & EB (\%) \\
\hline VPP & $533 \pm 145^{\mathrm{a}}$ & $25.5 \pm 3.6^{\mathrm{a}}$ & $72 \pm 22^{\mathrm{bc}}$ \\
RPP & $349 \pm 71^{\mathrm{d}}$ & $19.9 \pm 2.8^{\mathrm{c}}$ & $692 \pm 28^{\mathrm{a}}$ \\
$50 \mathrm{VPP} / 50 \mathrm{RPP}$ & $473 \pm 123^{\mathrm{ab}}$ & $23.5 \pm 2.1^{\mathrm{b}}$ & $199 \pm 209^{\mathrm{b}}$ \\
\hline NC-1OCN & $530 \pm 75^{\mathrm{a}}$ & $24.0 \pm 1.6^{\mathrm{ab}}$ & $36 \pm 15^{\mathrm{d}}$ \\
NC-3OCN & $493 \pm 114^{\mathrm{ab}}$ & $19.3 \pm 1.7^{\mathrm{cd}}$ & $21 \pm 6^{\mathrm{d}}$ \\
NC-5OCN & $425 \pm 96^{\mathrm{bc}}$ & $17.1 \pm 1.0^{\mathrm{e}}$ & $24 \pm 8^{\mathrm{d}}$ \\
\hline NC-1OCP & $538 \pm 68^{\mathrm{a}}$ & $22.8 \pm 1.6^{\mathrm{b}}$ & $59 \pm 42^{\mathrm{cd}}$ \\
NC-3OCP & $379 \pm 96^{\mathrm{cd}}$ & $17.9 \pm 2.0^{\mathrm{de}}$ & $56 \pm 59^{\mathrm{cd}}$ \\
NC-5OCP & $334 \pm 9^{\mathrm{d}}$ & $12.9 \pm 1.1^{\mathrm{f}}$ & $41 \pm 18^{\mathrm{d}}$ \\
\hline
\end{tabular}

YM: Young's modulus. TS: tensile strength. EB: elongation at break. Superscripts a-f indicate significant differences for the same parameter among films, according to the ANOVA analysis and Fisher LSD test $(p<0.05)$.

On the other hand, mechanical parameters of the nanocomposites depended more on the resulting polymer/clay structures formed than their crystallinities, which were similar at all concentrations (see Table 4). YM tended to increase at $1 \mathrm{wt} \%$ nanoclay compared to the control VPP/RPP blend associated with the rigidity of the silicate structures, which display a high aspect ratio, and the immobilization of polymer chains intercalated between the clay mineral layers. Nonetheless, the elastic modulus of the nanocomposites containing OCP at 3 and $5 \mathrm{wt} \%$ decreased with a statistically significant difference, which can be attributed to the lower intercalation of PP chains between OCP layers at high clay concentration, as was observed earlier by XRD analysis. Furthermore, TS decreased at high clay concentration, possibly due to the greater formation of tactoid structures and an apparent poorer adhesion clay/polymer matrix observed by XRD and TGA, respectively.

Deformation at break values of the nanocomposites were significantly lower than EB values of VPP/RPP blend and closer to the VPP deformation (Table 4). These results were statistically similar regardless of the clay type and concentration. Nonetheless, EB of the nanocomposites with OCN were significantly lower than in the VPP. Besides, EB tended to slightly decrease with clay concentration, possibly due to a higher amount of tactoids that hindered energy dissipation through nanocomposite when this undergoes tensile stress causing the premature breakage [23]. Thus, interestingly, the incorporation of nanoclays not only counteract the effect of the degraded PP chains but also the great impact of the presence of pollutant polymers on the deformation behavior of the RPP. Higher standard deviations for EB results can be associated with different chain length distributions and pollutant compositions for each polymer batch, creating different numbers of tension points in the film.

Based on these results, the NC-1OCN nanocomposite had the most improved mechanical parameters, mainly elastic modulus and tensile strength, in accordance with the higher intercalation of PP chains between clay mineral layers, as it was previously observed through XRD due to the greater affinity of the hydrophobic organic modifier of OCN with PP.

\subsection{Overall Migration Results}

If recycled polymers are intended to be applied as food contact packaging materials, analyzing the effect of the recycling processes on their safety is necessary. Thus, overall migration studies of RPP nanocomposites under three different food simulants were carried out to understand their dependence on the type of packaged food. The overall migration values from VPP, RPP, 50VPP/50RPP and NC films at $1 \mathrm{wt} \%$ of clay, which had the best mechanical performance are shown in Table 5. 
Table 5. Overall migration from control and nanoreinforced films to different food simulants.

\begin{tabular}{|c|c|c|}
\hline Food Simulant & Film & $\begin{array}{l}\text { Overall Migration } \\
\quad\left(\mathrm{mg} \mathrm{dm}^{-2}\right)\end{array}$ \\
\hline \multirow{5}{*}{ Fatty } & VPP & $6.72 \pm 0.49^{\mathrm{a}}$ \\
\hline & $\mathrm{RPP}$ & $27.19 \pm 0.86^{\mathrm{e}}$ \\
\hline & 50VPP/50RPP & $19.34 \pm 0.15^{\mathrm{d}}$ \\
\hline & NC-1OCN & $17.86 \pm 0.14^{c}$ \\
\hline & NC-1OCP & $16.62 \pm 0.11^{b}$ \\
\hline \multirow{3}{*}{ Non acid } & 50VPP/50RPP & $0.30 \pm 0.07^{\mathrm{a}}$ \\
\hline & NC-1OCN & $0.42 \pm 0.38^{\mathrm{a}}$ \\
\hline & NC-1OCP & $0.66 \pm 0.32^{\mathrm{a}}$ \\
\hline \multirow{3}{*}{ Acid } & 50VPP/50RPP & $0.37 \pm 0.07^{\mathrm{a}}$ \\
\hline & NC-1OCN & $0.46 \pm 0.16^{\mathrm{a}}$ \\
\hline & NC-1OCP & $0.56 \pm 0.04^{\mathrm{a}}$ \\
\hline
\end{tabular}

Superscripts a-d indicate significant differences among films for each type of simulant according to the ANOVA analysis and Fisher LSD test $(p<0.05)$.

The overall migration from 100\% VPP and RPP control films was determined in a fatty food simulant, considering that this medium caused the maximum migration due to the greater affinity between fatty simulant and PP. A higher RPP percentage in the films without clay significantly increased migration, with a 2.9 and 4 -fold increase for $50 \%$ and $100 \%$ RPP samples, respectively.

The current European Union Regulation (No. 10/2011 of the Commission of 14 January 2011) establishes an overall migration limit of $10 \mathrm{mg} \mathrm{dm}^{-2}$ from plastics to be used in direct contact with food, equivalent to $60 \mathrm{mg}$ per $\mathrm{kg}$ of food occupying a volume of a cubic package with $6 \mathrm{dm}^{2}$ of total area. Thus, RPP-based films in the fatty simulant at the conditions studied exceeded this limit. However, the EU normative $\left(\mathrm{N}^{\circ} 10 / 2011\right.$ with modification 2016/1416) considers applying fat reduction factors to migration values for food categories using a D2 fat simulant at the predictable conditions of use.

In the fatty simulant, the incorporation of the nanoclays in the PP matrix decreased the overall migration probably due to tortuous pathways created by clay mineral layers that increased the barrier properties, and therefore, hindered migration from the polymer. This phenomenon has been similarly observed for RPET/clay nanocomposites [21].

The nanocomposite containing OCP exhibited a more significant decrease of the overall migration in the fatty simulant, probably due to some polarity of the OCP organic modifier containing hydroxyl groups, which inhibited the interaction of the hydrophobic simulant with the nanocomposite.

Conversely, overall migrations from 50VPP/50RPP control and nanocomposites films in the acidic and non-acidic aqueous simulants were far below $\left(<1 \mathrm{mg} \mathrm{dm}^{-2}\right)$ than migration values obtained in fatty simulants. Besides, no statistically significant differences were observed between the 50VPP/50RPP control film and nanocomposites. However, it can be noted that nanocomposites with OCP showed a slight tendency to increase migration compared to films with OCN. These results highlighted the effect of the higher hydrophilicity of the OCP, which increased the affinity between the nanocomposite and aqueous simulants, causing a greater penetration of the simulant in the polymeric matrix and a higher release of their components.

\section{Conclusions}

The nanocomposite at $1 \mathrm{wt} \%$ of OCN had the best thermal and mechanical performance at the studied conditions. The highest intercalation grade of PP between clay mineral layers was reached with OCN because its organic modifier is more hydrophobic. Pollutant polymer traces in the RPP drastically increased its ductility. Interestingly, nanoclay incorporation caused a reduction of the elongation at break of the RPP/VPP film, although it did not significantly increase Young's modulus and tensile strength, which 
were instead reduced at high clay percentage. The latter can be due to a greater amount of tactoids or clay particles poorly attached to the polymer matrix, considering crystallinities were similar for all nanocomposites.

Conversely, the overall migration values of nanocomposites to $3 \%$ acetic acid and $10 \%$ ethanol food simulants were lower than $1 \mathrm{mg} \mathrm{dm}^{-2}$, far below the limit ruled by current European legislation. Meanwhile, the overall migration of free-clay RPP-based films and the nanocomposites in fatty simulant exceeded that limit, and, although the incorporation of nanoclays exerted a barrier effect, migration values were still higher than the allowed limit. Nonetheless, fat reduction factors can be applied in an adequate fatty simulant according to current European legislation for plastics to be used in specific food categories and predictable use conditions. Finally, it is highlighted that the clay with the most hydrophobic organic modifier improved the thermal properties, the intercalation grade and some mechanical parameters of the VPP/RPP blend, but increased the affinity of the fatty simulant towards nanocomposites and overall migration to that food simulant.

Supplementary Materials: The following are available online at https:/ / www.mdpi.com/article/10 .3390/polym13091502/s1, Table S1: Tensile parameters of VPP/RPP films.

Author Contributions: Conceptualization, E.V., C.L.d.D.; methodology, E.V., X.V.; formal analysis, E.V., L.G.; investigation, S.E.; resources, M.J.G., A.G.; data curation, S.E., L.G.; writing-original draft preparation, E.V.; writing-review and editing, C.L.d.D.; supervision, C.L.d.D., M.J.G., A.G.; project administration, M.J.G., C.L.d.D.; funding acquisition, C.L.d.D., M.J.G., A.G. All authors have read and agreed to the published version of the manuscript.

Funding: This work was supported by the "Programa de Financiamiento Basal para Centros Científicos y Tecnológicos de Excelencia" (Project AFB180001), Directorate of Scientific and Technological Research of the University of Santiago, Chile (DICYT-USACH) and USA1956_DICYT Res. 202115096.

Institutional Review Board Statement: Not applicable.

Informed Consent Statement: Not applicable.

Data Availability Statement: Not applicable.

Conflicts of Interest: The authors declare no conflict of interest.

\section{References}

1. Plastics Europe Market Research Group and Conversio Market \& Strategy GmbH. 2019. Available online: https://www. plasticseurope.org/application/files/9715/7129/9584/FINAL_web_version_Plastics_the_facts2019_14102019.pdf (accessed on 1 April 2021).

2. Yin, S.; Tuladhar, R.; Shi, F.; Shanks, R.A.; Combe, M.; Collister, T. Mechanical reprocessing of polyolefin waste: A review. Polym. Eng. Sci. 2015, 55, 2899-2909. [CrossRef]

3. Zdiri, K.; Elamri, A.; Hamdaoui, M.; Harzallah, O.; Khenoussi, N.; Brendlé, J. Reinforcement of recycled PP polymers by nanoparticles incorporation. Green Chem. Lett. Rev. 2018, 11, 296-311. [CrossRef]

4. Vasile, C. Polymeric Nanocomposites and Nanocoatings for Food Packaging: A Review. Materials 2018, 11, 1834. [CrossRef]

5. Zdiri, K.; Elamri, A.; Hamdaoui, M.; Khenoussi, N.; Harzallah, O.; Brendle, J. Impact of Tunisian clay nanofillers on structure and properties of post-consumer polypropylene-based nanocomposites. J. Thermoplast. Compos. Mater. 2019, 32, 1159-1175. [CrossRef]

6. Zdiri, K.; Elamri, A.; Hamdaoui, M.; Harzallah, O.; Khenoussi, N.; Brendlé, J. Valorization of Post-consumer PP by (Un)modified Tunisian Clay Nanoparticles Incorporation. Waste Biomass-Valorization 2020, 11, 2285-2296. [CrossRef]

7. Zdiri, K.; Harzallah, O.; Elamri, A.; Khenoussi, N.; Brendlé, J.; Mohamed, H. Rheological and thermal behavior of Tunisian clay reinforced recycled polypropylene composites. Adv. Polym. Technol. 2018, 37, 3759-3768. [CrossRef]

8. Al-Samhan, M.; Samuel, J.; Al-Attar, F.; Abraham, G. Comparative Effects of MMT Clay Modified with Two Different Cationic Surfactants on the Thermal and Rheological Properties of Polypropylene Nanocomposites. Int. J. Polym. Sci. 2017, 2017, 1-8. [CrossRef]

9. De Dicastillo, C.L.; Velásquez, E.; Rojas, A.; Guarda, A.; Galotto, M.J. The use of nanoadditives within recycled polymers for food packaging: Properties, recyclability, and safety. Compr. Rev. Food Sci. Food Saf. 2020, 19, 1760-1776. [CrossRef]

10. Kuorwel, K.K.; Cran, M.J.; Orbell, J.D.; Buddhadasa, S.; Bigger, S.W. Review of Mechanical Properties, Migration, and Potential Applications in Active Food Packaging Systems Containing Nanoclays and Nanosilver. Compr. Rev. Food Sci. Food Saf. 2015, 14, 411-430. [CrossRef] 
11. Farhoodi, M. Nanocomposite Materials for Food Packaging Applications: Characterization and Safety Evaluation. Food Eng. Rev. 2015, 8, 35-51. [CrossRef]

12. Nile, S.H.; Baskar, V.; Selvaraj, D.; Nile, A.; Xiao, J.; Kai, G. Nanotechnologies in Food Science: Applications, Recent Trends, and Future Perspectives. Nano-Micro Lett. 2020, 12, 1-34. [CrossRef]

13. Materials, E.E.P.O.F.C.; Flavourings, E.P.O.F.C.M.E.; (Cef), P.A. Safety assessment of the substance montmorillonite clay modified by dimethyldialkyl(C16-C18)ammonium chloride for use in food contact materials. EFSA J. 2015, 13, 4285. [CrossRef]

14. Xia, Y.; Rubino, M.; Auras, R. Chapter Seven-Interaction of nanoclay-reinforced packaging nanocomposites with food sim-ulants and compost environments. In Food Applications of Nanotechnology; Lim, L.-T., Rogers, M.B.T.-A., Eds.; Academic Press: Cambridge, MA, USA, 2019; Volume 88, pp. 275-298. ISSN 1043-4526.

15. Bott, J.; Franz, R. Investigatio into the Potential Migration of Nanoparticles from Laponite-Polymer Nanocomposites. Nanomaterials 2018, 8, 723. [CrossRef] [PubMed]

16. Xia, Y.; Rubino, M.; Auras, R. Release of Nanoclay and Surfactant from Polymer-Clay Nanocomposites into a Food Simulant. Environ. Sci. Technol. 2014, 48, 13617-13624. [CrossRef]

17. Farhoodi, M.; Mousavi, S.M.; Sotudeh-Gharebagh, R.; Emam-Djomeh, Z.; Oromiehie, A. Migration of Aluminum and Silicon from PET/Clay Nanocomposite Bottles into Acidic Food Simulant. Packag. Technol. Sci. 2013, 27, 161-168. [CrossRef]

18. Echegoyen, Y.; Rodríguez, S.; Nerín, C. Nanoclay migration from food packaging materials. Food Addit. Contam. Part A 2016, 33, 530-539. [CrossRef]

19. Jablonski, J.E.; Yu, L.; Malik, S.; Sharma, A.; Bajaj, A.; Balasubramaniam, S.L.; Bleher, R.; Weiner, R.G.; Duncan, T.V. Migration of Quaternary Ammonium Cations from Exfoliated Clay/Low-Density Polyethylene Nanocomposites into Food Simulants. ACS Omega 2019, 4, 13349-13359. [CrossRef] [PubMed]

20. Han, C.; Zhao, A.; Varughese, E.; Sahle-Demessie, E. Evaluating weathering of food packaging polyethylene-nano-clay composites: Release of nanoparticles and their impacts. NanoImpact 2018, 9, 61-71. [CrossRef]

21. Velásquez, E.; Garrido, L.; Valenzuela, X.; Galotto, M.J.; Guarda, A.; de Dicastillo, C.L. Physical properties and safety of $100 \%$ post-consumer PET bottle -organoclay nanocomposites towards a circular economy. Sustain. Chem. Pharm. 2020, $17,100285$. [CrossRef]

22. Wunderlich, B. The ATHAS database on heat capacities of polymers. Pure Appl. Chem. 1995, 67, 1019-1026. [CrossRef]

23. Velásquez, E.; Garrido, L.; Guarda, A.; Galotto, M.; De Dicastillo, C.L. Increasing the incorporation of recycled PET on polymeric blends through the reinforcement with commercial nanoclays. Appl. Clay Sci. 2019, 180, 105185. [CrossRef]

24. Vyncke, G.; Fiorio, R.; Cardon, L.; Ragaert, K. The effect of polyethylene on the properties of talc-filled recycled polypropylene. Plast. Rubber Compos. 2020, 1-8. [CrossRef]

25. Kim, H.; Biswas, J.; Choe, S. Effects of stearic acid coating on zeolite in LDPE, LLDPE, and HDPE composites. Polymer 2006, 47, 3981-3992. [CrossRef]

26. Curtzwiler, G.W.; Schweitzer, M.; Li, Y.; Jiang, S.; Vorst, K.L. Mixed post-consumer recycled polyolefins as a property tuning material for virgin polypropylene. J. Clean. Prod. 2019, 239, 117978. [CrossRef]

27. Strömberg, E.; Karlsson, S. The design of a test protocol to model the degradation of polyolefins during recycling and service life. J. Appl. Polym. Sci. 2009, 112, 1835-1844. [CrossRef]

28. Graziano, A.; Jaffer, S.; Sain, M. Review on modification strategies of polyethylene/polypropylene immiscible thermoplastic polymer blends for enhancing their mechanical behavior. J. Elastomers Plast. 2018, 51, 291-336. [CrossRef]

29. Swain, S.K.; Isayev, A.I. Effect of ultrasound on HDPE/clay nanocomposites: Rheology, structure and properties. Polymer 2007, 48, 281-289. [CrossRef]

30. Kanagaraj, S.; Varanda, F.R.; Zhil'Tsova, T.V.; Oliveira, M.S.; Simões, J.A. Mechanical properties of high density polyethylene/carbon nanotube composites. Compos. Sci. Technol. 2007, 67, 3071-3077. [CrossRef] 